\title{
Development and validation of the Mothers of Preterm Babies Postpartum Depression Scale
}

\author{
Ajibola A. Ishola ${ }^{1}$, Chisom C. Obasi ${ }^{1}$, Ismail T. Sholuke ${ }^{1}$
}

\begin{abstract}
Postpartum depression, a common complication in childbearing women, is of great public health concern. Previous screening tools have focused on depressed mood, with less attention paid to postpartum anxiety and suicidal ideation. This study developed and validated a tool to measure postpartum depression among mothers of preterm babies. From the clinical interviews and a pilot survey $(n=121)$ the Mothers of Preterm Babies Postpartum Depression Scale was developed. The Mothers of Preterm Babies Postpartum Depression Scale and the Edinburgh Postnatal Depression Scale questionnaires were completed by 152 mothers who delivered preterm babies at Massey Street Children's Hospital, Lagos. Data were analyzed with use of confirmatory factor analysis, principal component analysis, and Cronbach's alpha at the $P \leq 0.05$ level of significance. The new scale demonstrated a reliability $(\alpha)$ of 0.91 . Construct validity with exploratory factor analysis (Kaiser-Meyer-Olkin measure 0.70) yielded three dimensions of cognitive and emotional difficulty ( $\alpha=0.92$ ), hopelessness and suicidal ideation ( $\alpha=0.93)$, and physiological distress $(\alpha=0.71)$. Confirmatory factor analysis demonstrated a good fit: 18 degrees of freedom; goodness of fit index 0.97; adjusted goodness of fit index 0.93; and root mean square error of approximation 0.04. Convergent validity was established with the Edinburgh Postnatal Depression Scale $(r=0.66, P=0.00)$. The new screening tool was demonstrated to have meritorious validity, faster and easier to administer to the obstetric population.
\end{abstract}

Keywords: Postpartum depression; mothers of preterm babies; validity; reliability; obstetric population

Significance statement: Having a baby is often marked by disturbance in mood, and the birth of a premature baby can put mothers at greater risk of psychological distress than the birth of a fullterm baby. Available screening tools assess postpartum depression symptoms without consideration of mitigating sources of postpartum stress. Edinburgh Post-natal Depression scale is the commonest measure for differential diagnosis in Nigeria but limited in screening women for suicidal ideation and anxiety. This study developed a new tool that improves the efficiency of, and reduces the time spent diagnosing postpartum depression among mothers of preterm babies. Efficiency in diagnosing the pathological reaction of mothers of preterm babies to the child's condition and the corresponding depression symptoms is highly important for implementation of cost-effective intervention by mental health practitioners.

1. Department of Psychology, University of Ibadan, Ibadan, Nigeria

CORRESPONDING AUTHORS: Ajibola A. Ishola and Chisom C. Obasi

Department of Psychology, University of Ibadan, Ibadan, Nigeria

E-mail: ajibola_ishola@yahoo. co.uk (A.A. Ishola), chisomobasi@ yahoo.com (C.C. Obasi)

Received 29 March 2017; Accepted 12 March 2018 


\section{Introduction}

Postpartum depression is one of the commonest complications of childbearing among women (mostly poorly diagnosed). It has become a great public health concern as it affects a great proportion of women and their families in sub-Saharan Africa. The disruptive consequences of postpartum depression on the mother, family, marital relationship, and children make effective diagnosis, treatment, and prevention of this psychological disorder crucial [1]. Postpartum depression usually manifests itself from a few weeks up to more than 1 year after delivery with or without intervention among women of childbearing age [2].

The symptoms include hopelessness, low self-esteem, lack of sleep, and perceived incompetence in parenting and nursing ability. They also include poor eating habit, declining cognitive attention, inability to derive pleasure from pleasurable activities, and suicidal ideation [2]. Postpartum vulnerability encompasses comorbidity with affective disorders and psychosis. Postpartum depression may resolve spontaneously or with little intervention, while in many instances its victims require chemotherapy, psychotherapy, or both, and comorbidity with psychotic symptoms requires hospitalization and special psychiatric multidisciplinary treatment [3]. The average prevalence is on the increase; worldwide the prevalence is $10-15 \%$ [2]. The prevalence is increasing in Nigeria: a prevalence of $44.5 \%$ was reported in north central Nigeria [4], 30.6\% in southeast Nigeria [5], 14.6\% in southwest Nigeria [6], and $23 \%$ in south south Nigeria [7]. In these studies there was wide use of the Edinburgh Postnatal Depression Scale [8] in the measurement of depression after childbirth in Nigeria with meritorious reliability [7, 9-12].

Despite these trends, untreated postpartum depression is on the increase. Thus there is increasing need to assess and measure the contribution of the delivery of preterm babies to postpartum depression and the long-term effects on preterm mothers. Having a preterm baby can be a precursor of chronic or recurrent depression among mothers of preterm babies.

Eight hundred thousand preterm babies are born in Nigeria every year, making the country the third on the list of countries with the highest burden of preterm births worldwide, following India and China [13, 14]. Globally, prematurity is the leading cause of child death among those younger than 5 years, and is on the increase. From established data, 50\% of preterm births in developing countries end in death as a result of the lack of cost-effective care that can provide essential warmth, breastfeeding support, and basic care for respiratory infections and problems $[13,14]$. Preterm births occur for different reasons: because of early induction of labor or cesarean birth, and medical or nonmedical reasons. Common causes include multiple pregnancies, infections, and chronic conditions, such as diabetes and high blood pressure; however, often no cause is identified. A genetic influence has also been implicated [14]. In Nigeria, there is a high death rate among preterm babies born at 28 weeks or less occasioned by a high rate of developmental problems. Most children born preterm experience learning disabilities, attention deficit, other developmental problems (i.e., movement, visual), feeding difficulties, cerebral palsy, deafness, ulcers, and scars on their limbs, which make them require a lot of attention, support, and care for full functionality. This places a heavy burden on their mothers [14]. Mothers of premature babies often go into depression, anxiety, and despair over issues that their babies are not feeding or growing well, are doing so too slowly for their age, and do not have the general capability and maturity required of their age group. The mothers often express a high sense of failure, a heavy care burden, and difficulty looking after preterm babies. These mothers often experience a high level of anxiety until their children are close to adolescence, when they can be more comfortable with parenting. Postpartum depression has complications that include an impaired relationship or bonding between the mother, child, and intimate partner, leading to marital instability and childhood developmental problems.

Postpartum depression is infrequently diagnosed and indeed treated, despite its significant incidence and morbidity among mothers of preterm babies. Diagnosis of postpartum symptoms entails assessment of behaviors such as the mother's reactions during the period of adjustment to the new physiological, social, and behavioral conditions, including anxiety and fatigue. The routine use of screening scales for the purpose of identifying symptoms of depression is an effective, simple, and economical way to identify women at risk. In addition, most questionnaires specifically designed for the screening of postpartum depression fail to differentiate the affective from the physical symptoms and physiological changes that are typical of the puerperium, such as fatigue and changes in sleep pattern and eating habits peculiar to mothers 
of preterm babies. Presently, health care professionals working with the obstetric population use the Edinburgh Postnatal Depression Scale as an essential tool in their diagnosis of postpartum depression. However, clinicians who use this scale as a postpartum screening tool often need additional follow-up questions for the differential diagnosis of chronic depression, especially when they are screening patients for suicidal ideation. Previous measures of postpartum depression focused on depressed mood, with no attention to postpartum anxiety, which is just as prevalent. The purpose of this study was to develop a new, brief screening measure to identify postpartum distress among mothers of preterm babies, which is defined as symptoms of depression, anxiety, and suicidal ideation in conjunction with the mother's reaction to the child's condition.

\section{Method}

This is an ex post facto study that used a cross-sectional survey approach structured and questionnaire to collect information from the study participants. Women whose child was 4 weeks old on admission were assessed for depression by hospital psychiatrists using the Edinburgh Postnatal Depression Scale and clinical interview to identify women needing support. Also, women identified during interviews with mothers during children's ward round as having symptoms of depression were subsequently referred by pediatricians for psychiatric evaluation to prevent postadmission problems. Women from these two incidents who had a high score on the Edinburgh Postnatal Depression Scale (>13) were consecutively recruited for the study. Women with psychiatric comorbidities, women with health problems, and women younger than 18 years were excluded from the study. Consecutive sampling was used to sample 124 consenting preterm mothers in the first study (exploratory) and 152 participants at Massey Street Children's Hospital, Lagos State, in the second study. The study was conducted between May 2015 and October 2017. Massey Street Children's Hospital is foremost a pediatric referral hospital owned by Lagos State. In an unpublished review, the hospital was reported to have recorded $20 \%$ of the neonatal admissions in the state in 2012.

\section{Instrumentation}

The study as previously explained is an ex post facto study, and therefore used a structured self-developed standardized questionnaire to collect relevant information from the participants of the study. The questionnaire is a newly developed scale that underwent the stipulated scale development process [15]. It was divided into different segments, with each segment tapping the variables of interest.

\section{Scale development}

The scale development process was in line with procedures advocated in previous literature $[15,16]$.

\section{Literature review and development of the item pool}

As a first step in our item pool generation, we reviewed the literature on postpartum depression and other scales developed previously to assess postpartum depression or similar qualities. This constituted the identification and exploration of themes that described postpartum depression among preterm mothers. The literature identified insomnia, emotional distress, anxiety, and physiological symptoms, such as stomach disturbances, body pains, and drug dependence. We then asked 12 mothers of preterm babies in whom postpartum depression had been diagnosed within 6 weeks of delivery to describe the frequent significant symptoms of depression experienced in the presence of their physicians. This was done through some open-ended questions, which gave an opportunity for respondents to freely express their thoughts. From the free responses, following the themes identified from the initial literature reviewed and guided by the DSM- 5 criteria for postpartum depression, we generated 63 items. To improve the articulateness and precision of the scale, the items were subjected to content validity using knowledge expert assessment.

\section{Validation of the item pool}

The content validity of the 63 items was determined through the use of knowledge expert assessment. Face validity was determined by five knowledge experts (one associate professor with a $\mathrm{PhD}$ degree and four graduate students with an MSc degree) with average experience of 6.12 years (standard deviation 2.54 years). They were considered to be experts in clinical and health psychology at the University of Ibadan. The items were assessed for understandability, clearness, accuracy, and appropriateness, and suggestions 
for improvement were made where necessary. The 63 items assessed by the experts were reduced to 22 items using the $80 \%$ averaged aggregate percentage score as a cutoff point for each item. Intraclass interrater reliability was 0.95 (21.75), $P=0.00$.

\section{Pilot study and exploratory factor analysis}

Copies of the edited and revised questionnaire containing 22 items were taken into the field and administered to 124 participants at Massey Street Children's Hospital. The questionnaire was scored with a Likert scoring format ranging from 1 for "not at all" or "never" to 5 for "most times" or "frequently experienced daily." The Edinburgh Postnatal Depression Scale was the second measure used to capture postpartum depression of mothers of preterm babies. This 10-item screening tool is scored by addition of the scores for each of the 10 items. Scores above 13 demonstrate severe depressive symptoms. This instrument has been used and validated in Nigeria. The reliability $(\alpha)$ of the scale is 0.67. Exploratory factor analysis, using varimax rotation, was used to test the dimensionality of the new scale structure to identify factors that correlated, and clarify the underlying dimensions. The criterion used to determine the number of factors to be retained was the Kaiser-Meyer-Olkin criterion (i.e., eigenvalues greater than 1 are retained), which is one of the most widely used. The items measuring the factors that were loaded were assessed for convergent validity, and the constructs' coefficients of reliability were calculated.

\section{Confirmatory factor analysis}

The data obtained from 152 mothers of preterm were used to test the factor solution determined by the exploratory factor analysis for structure stability and viability with use of IBM SPSS Amos version 24. Confirmatory factor analysis establishes if the factor structure/constructs emerging from the exploratory factor analysis are stable and describe the dimensions of the scale developed in the study. The factor structure obtained from exploratory factor analysis was matched with the factor structure in the analysis.

\section{Procedure}

The questionnaires were administered to mothers who had delivered preterm babies who were admitted to the children's intensive care unit at Massey Street Children's Hospital. Women identified as having depression by hospital psychiatrists using the Edinburgh Postnatal Depression Scale during mother-child ward interaction clinical interviews and those referred for depression evaluation by pediatricians were consecutively recruited for the study. Before administration of the questionnaire, their consent was sought, and those who indicated that they would participate in the study were given copies of the questionnaire to complete. This was done on an individual basis because it was made clear to them before they were given the questionnaires that they were not compelled to participate in the study and that their anonymity would be protected. The final questionnaire scale was then subjected to item analysis using confirmatory factor analysis, principal component analysis, Cronbach's alpha, and split half reliability with the aid of IBM SPSS Statistics version 20.0. and IBM SPSS Amos version 24.

\section{Ethical considerations}

Ethics approval for the study was granted by Lagos State Hospital Management Board (reference No:SHMB/720/Vol. VI). In the same vein, informed consent was obtained from each participant; informed consent stipulated the nonmalfeasance nature of the study, the right to withdraw from the study, and anonymity and privacy protection of the participants and data obtained in the study.

\section{Results}

Factor analysis $(n=124)$

An exploratory factor analysis was applied to explore the underlying dimensions of factors affecting postpartum depression. The average age was 35.45 years (standard deviation 3.26 years). The largest proportion of the respondents (54.0\%) were in the age range from 31 to 40 years, $37.9 \%$ were in the age range from 21 to 30 years, and $8.1 \%$ were in age range above 40 years; $89.5 \%$ were married and $10.5 \%$ were single mothers; $59.7 \%$ had completed only secondary school education, $15.3 \%$ had an ordinary national diploma, and $18.6 \%$ had first degree education; $46.8 \%$ were business owners, $32.3 \%$ were traders, $8.1 \%$ were civil servants, $6.5 \%$ were private organization employees, and $6.5 \%$ were full housewives; $62.1 \%$ were multigravidae and $12.5 \%$ were first time mothers; $62.1 \%$ of the 
Table 1. Factor analysis of principal component analysis with varimax rotation showing the dimensions of the Mothers of Preterm Babies Postpartum Depression Scale

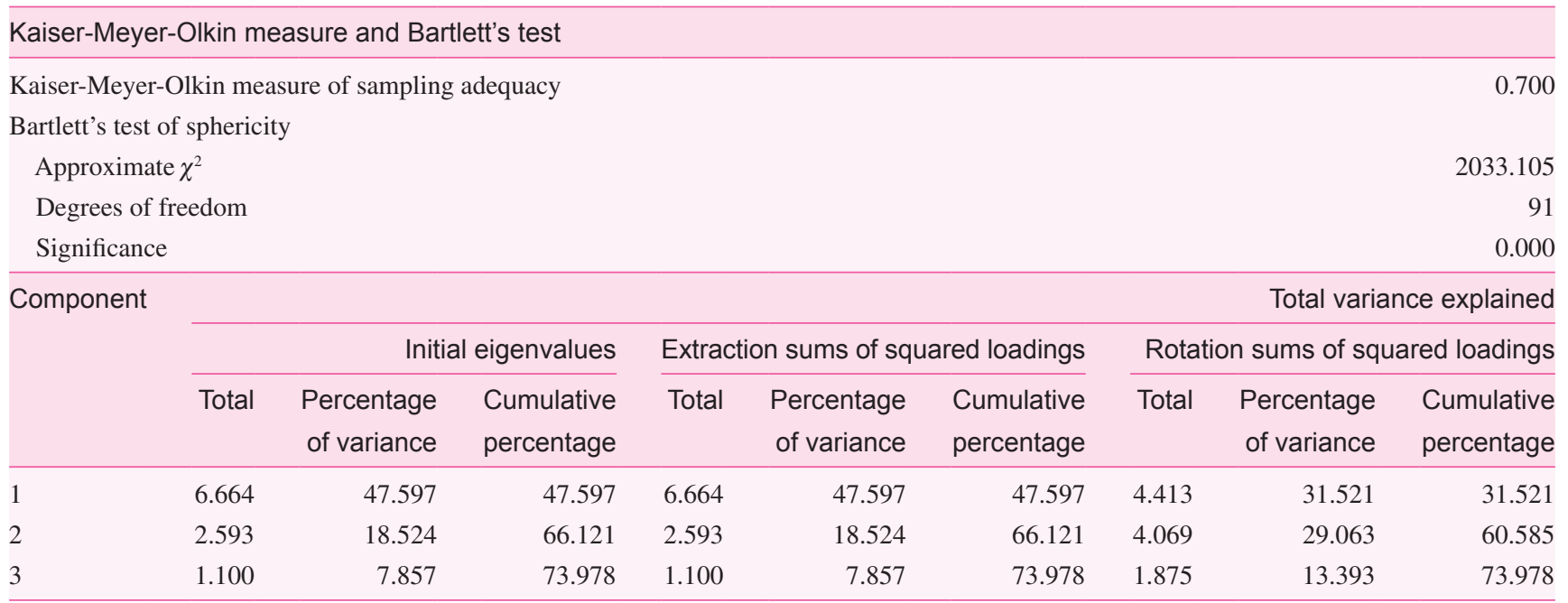

respondents had one or two children; $91.1 \%$ had experienced a normal birth and $8.9 \%$ had experienced cesarean delivery. The average gestation period was 30.3 weeks; $92.4 \%$ of babies were born before 37 weeks' gestation. Prevalent clinical symptoms among the preterm babies were sepsis (36\%), respiratory problems (42\%), neonatal hyperbilirubinemia (7\%), and other symptoms (15\%), which included perinatal asphyxia and nosocomial sepsis. Women with clinically diagnosed depression during pregnancy were excluded.

To determine the number of factors for the sample, exploratory factor analysis was performed, while descriptive statistics and initial communality factor scores were calculated. From the analysis, the initial result revealed a Kaiser-Meyer-Olkin measure of 0.5 , which was less than the recommended 0.6 cutoff point for a good fit for exploratory factor analysis. Seven items were identified to have poor or exaggerated loading on the basis of the initial communalities. These seven items were deleted on the basis of a loading performance cutoff of less than 0.40 and more than 0.90 , indicating exaggerated item loading on communalities. After deletion, the exploratory factor analysis $\chi^{2}$ goodness of fit rose to 0.70 , which indicated a moderately good fit (see Table 1 ).

First, the covariance contained in the correlation matrix was tested by use of the Bartlett test and the measure of sampling adequacy. In this test, the Bartlett test of sphericity
$(P=0.000)$ indicated the statistical probability that the correlation matrix has significant correlations, whereas the KaiserMeyer-Olkin measure of the measure of sampling adequacy was 0.70 , showing meritorious sampling adequacy. A factor structure explaining $73.98 \%$ of the variance was obtained. As verified by a Kaiser-Meyer-Olkin measure of $0.700, \chi^{2}$ $(91)=2033.11, P=0.000$, this suggests that the data matrix could be factorized (see Table 1). The principal axis factoring methods quantified the viability of value of a "factor" in terms of the amount of discrepancy between the matrix of observed correlations and those reproduced from the factor equations. The principal component analysis extraction with varimax rotation produced a three-factor solution that accounted for $73.98 \%$ of the variance in item responses. The factors obtained were the dimensions of cognitive and emotional difficulty, hopelessness and suicidal thought, and physiological distress. On the other hand, the factor loading for the items ranged from 0.544 to 0.922 , which indicated that all the items loaded well on the factors precipitated (see Table 2).

\section{Item analysis and reliability statistics}

The reliability derived from the item analysis revealed Cronbach's alpha to be 0.91 and the average interitem score to be 0.43 , showing a moderate level of reliability. The Gutmann reliability was 0.90 and McDonald's omega was 
Table 2. Factor analysis of principal component analysis with varimax rotation showing the dimensions of the Mothers of Preterm Babies Postpartum Depression Scale

\begin{tabular}{|c|c|c|c|}
\hline & \multicolumn{3}{|r|}{ Component } \\
\hline & $\begin{array}{l}\text { Cognitive and } \\
\text { emotional difficulty }\end{array}$ & $\begin{array}{l}\text { Hopelessness and } \\
\text { suicidal thought }\end{array}$ & $\begin{array}{r}\text { Physiological } \\
\text { distress }\end{array}$ \\
\hline & $\alpha=0.93$ & $\alpha=0.92$ & $\alpha=0.71$ \\
\hline $\begin{array}{l}\text { Neglecting personal care and family members because of total concerns } \\
\text { about the baby }\end{array}$ & 0.922 & & \\
\hline $\begin{array}{l}\text { Difficulty concentrating when carrying out daily routine tasks (washing, } \\
\text { cooking, cleaning) }\end{array}$ & 0.834 & & \\
\hline Preterm baby care; time-consuming and very stressful & 0.831 & & \\
\hline Feeling tired and lacking energy most times & 0.819 & & \\
\hline $\begin{array}{l}\text { Abuse or misuse of analgesic and antacid to ward off physical, emotional, } \\
\text { and psychic pain }\end{array}$ & 0.769 & & \\
\hline Suffers loss of memory in recent times & 0.755 & & \\
\hline Feeling empty when looking at baby ${ }^{*}$ & & 0.920 & \\
\hline Feeling like ending it all for me or the baby to stop being burden to others & & 0.888 & \\
\hline $\begin{array}{l}\text { Persistent anxiety that the baby's condition can never get better (fear of } \\
\text { wasting time, energy, and resources) }\end{array}$ & & 0.857 & \\
\hline Feeling of hopelessness about baby’s condition & & 0.823 & \\
\hline Feeling guilty about baby's condition & & 0.809 & \\
\hline Suffers from persistent heartburn and indigestion & & & 0.879 \\
\hline Poor eating habit and appetite & & & 0.647 \\
\hline Consistently having body pains and head ache & & & 0.544 \\
\hline
\end{tabular}

The extraction method was principal component analysis, and the rotation method was varimax with Kaiser normalization.

*Rotation converged in five iterations. Item removed in the reliability analysis.

Table 3. Reliability statistics showing the reliability of the Mothers of Preterm Babies Postpartum Depression Scale

\begin{tabular}{rrrrrrr}
\hline & & & & & Item reliability statistics \\
\hline Mean & SD & Cronbach's & Gutmann's & McDonald's & Average interitem & $95.0 \%$ Confidence limit \\
& & $\alpha$ & $\lambda_{6}$ & $\omega$ & correlation & Lower \\
\hline 4.453 & 0.265 & 0.908 & 0.902 & 0.977 & 0.427 & 0.875 \\
\hline
\end{tabular}

$\mathrm{SD}$, standard deviation.

0.98 (see Table 3). This demonstrated that more than $90 \%$ of the respondents were constituent in responding to items on the scale. This implied a strong internal consistency. Further item analysis with total item correlations is presented in Table 4. The reliability derived from the item analysis revealed Cronbach's alpha to be 0.91 . The 14 items were found to have high total item correlation following the 0.3 standard set by scholars [17, 18]. The split half reliability, another measure consistency, revealed that the Spearman-Brown coefficient was 0.90 . When the items were split into two groups, group A consisting of seven items had Cronbach's alpha of 0.86 and group B consisting of seven items has Cronbach's alpha of 0.89 . The correlation between forms of 0.71 showed a sound level of internal homogeneity and strong reliability. 
Table 4. Reliability statistics showing the item-rest correlation of total item correlation

\begin{tabular}{|c|c|c|c|c|c|c|}
\hline & & & & & & If item dropped \\
\hline & Mean & SD & Item-rest correlation & Cronbach's $\alpha$ & Gutmann's $\lambda_{6}$ & McDonald's $\omega$ \\
\hline b3 & 4.710 & 0.944 & 0.596 & 0.896 & 0.971 & 0.907 \\
\hline b4 & 4.758 & 0.849 & 0.589 & 0.897 & 0.972 & 0.907 \\
\hline b5 & 4.815 & 0.703 & 0.705 & 0.895 & 0.971 & 0.904 \\
\hline b6 & 4.863 & 0.642 & 0.718 & 0.895 & 0.972 & 0.903 \\
\hline b7 & 4.629 & 0.975 & 0.593 & 0.896 & 0.972 & 0.908 \\
\hline b13 & 4.169 & 1.215 & 0.678 & 0.892 & 0.975 & 0.908 \\
\hline b14 & 4.169 & 1.354 & 0.687 & 0.892 & 0.972 & 0.908 \\
\hline b15 & 4.234 & 1.338 & 0.740 & 0.889 & 0.971 & 0.907 \\
\hline b16 & 4.395 & 1.167 & 0.648 & 0.894 & 0.972 & 0.909 \\
\hline b17 & 4.540 & 1.062 & 0.471 & 0.901 & 0.978 & 0.913 \\
\hline b22 & 3.782 & 1.479 & 0.414 & 0.905 & 0.978 & 0.915 \\
\hline b31 & 4.089 & 1.337 & 0.621 & 0.896 & 0.974 & 0.910 \\
\hline b33 & 4.202 & 1.420 & 0.714 & 0.891 & 0.972 & 0.907 \\
\hline b39 & 4.363 & 1.205 & 0.471 & 0.901 & 0.976 & 0.914 \\
\hline
\end{tabular}

SD, standard deviation.

\section{Confirmatory factor analysis $(n=152)$}

In the confirmatory factor analysis, a consecutive sample of 152 mothers of preterm babies who had given birth in the previous 5 months were sampled with a consecutive sampling technique from Massey Street Children's Hospital. The average age was 34.6 years, with a standard deviation of 3.67 years. Ninety percent were married and $10 \%$ were single. Sixty-five percent of the respondents were multigravidae, $88 \%$ had given birth vaginally, and $12 \%$ had given birth by cesarean delivery. The average gestation period was 30.3 weeks, and $92.4 \%$ of babies were born before 37 weeks' gestation. Prevalent clinical symptoms among the preterm babies in this population were respiratory problems $(63.1 \%)$ and sepsis $(25 \%)$. Women with a history of depression during pregnancy and other related psychological disorders were excluded. The mean Mothers of Preterm Babies Postpartum Depression Scale score for the 152 sampled respondents was 62.51 (standard deviation 9.27, range 24-70) for the 14 items derived from the exploratory factor analysis.

Confirmatory factor analysis of the Mothers of Preterm Babies Postpartum Depression Scale was performed by maximum likelihood estimation for the total sample $(n=154)$. The stability of the three-factor model identified from the exploratory factor analysis was tested with IBM SPSS Amos version 24 [19]. Each of the 14 items was allowed to load on only a single factor of the three factors, while the relationship among latent variables was assessed as no residual from each of the items that was assumed to be correlated. The model fit was assessed with the following fit indices: $\chi^{2}$ goodness-offit statistic, the comparative fit index (CFI), the Tucker-Lewis index (TLI), the root mean square error of approximation (RMSEA), and the standardized root mean square residual (SRMR). The $\chi^{2}$ statistic measured the degree of discrepancy between the sample and fitted covariance matrices. A close fit of the model to the data will yield a nonsignificant $P$ value. However, this statistic is very sensitive to sample size and nonnormality; therefore other fit indices must also be used to evaluate model fit. $\mathrm{Hu}$ and Bentler [20] proposed a cutoff value for these fit indices as follows: values of CFI and TLI above 0.95 are recognized as a meritorious fit, RMSEA values below 0.06 identify a good fit, and SRMR values less than 0.08 suggests a good fit. The results of initial confirmatory analysis with the full 14 items had a poor fit $\left(\chi^{2}=708,74\right.$ degrees of freedom, $P<0.01, \mathrm{CFI}=0.65$, TLI $=0.599$, adjusted goodness of fit index [AGFI] of 0.512, RMSEA $=0.24$, SRMR $=0.12$ ). However, use of the modification indices 
specified for this model analysis with IBM SPSS Amos permitted residuals from some of the items to correlate with each other to improve the model fit. The model showed a significant improvement: $\chi^{2}=55.97,41$ degrees of freedom, $P=0.06$, CFI $=0.99$, TLI $=0.99$, AGFI $=0.877$, RMSEA $=0.07(90 \%$ confidence interval $0.0-0.08$ ), and $S R M R=0.07$. Further assessment showed that five items were redundant, and these were subsequently removed, and some of the earlier modification index adjustments by allowing residuals of some items to correlate with one another further improved the model fit. The residual correlations $r=0.43$ for items 15 and $17, r=-0.80$ for items 14 and 6, $r=0.3$, for items 15 and 13, $r=0.17$ for items 3 and $6, r=-0.13$ for items 3 and 5 , and $r=-0.76$ for items 22 and 17 were significant. Therefore the model fitness showed a significant improvement: $\chi^{2}=22.06,18$ degrees of freedom, $P=0.23, \mathrm{CFI}=0.97, \mathrm{AGFI}=0.925$, TLI $=0.99$, RMSEA $=0.039$ (90\% confidence interval 0.0-0.086), and $\mathrm{SRMR}=0.05$. This final three-factor model is presented in Table 5 .

\section{Internal construct validity of the final nine-item Moth- ers of Preterm Babies Postpartum Depression Scale}

The internal consistency (Cronbach's alpha) was adequate for each of the three factors, all of which exceeded the 0.70 criterion of minimally acceptable reliability as suggested by Nunally and Rubestein [21] (Table 6). The internal consistency was 0.86 for the Mothers of Preterm Babies Postpartum Depression Scale total score. Factor-based scores were derived from the unweighted sums of the items loading significantly on a given factor. The correlation analysis revealed that the three factors correlated significantly with each other. "Hopelessness and suicidal thought" and "physiological distress" have the stronger association as feelings of hopelessness and suicidal thought tend to be strongly associated with physiological distress (see Table 7).

\section{Convergent validity}

Convergent validity was assessed by use of Pearson correlation analysis. Scores on the Mothers of Preterm Babies Postpartum Depression Scale were correlated with scores on the Edinburgh Postnatal Depression Scale. The scale measures the extent to which mothers of preterm babies exhibit postpartum depression. The Pearson correlation analysis revealed that there was a significant positive relationship between postpartum depression and the Edinburgh Postnatal Depression Scale score $(r=0.658$ $P=0.000)$. Postpartum depression increases in the same direction for the Edinburgh Postnatal Depression Scale and the Mothers of Preterm Babies Postpartum Depression Scale.

\section{Norm}

The norm was set with use of the average score one standard deviation above the mean (64.63). A high score above the cutoff score indicated that the respondents had postpartum depression, while lower scores above the mean $(\bar{x}=56.84)$ suggested that the patients were at risk of partum depression (see Table 8).

\section{Discussion}

The reliability derived from the Cronbach alpha analysis revealed that the new scale [mothers of preterm babies postpartum depression (MPBPD)] had meritorious reliability. The

Table 5. Confirmatory factor analysis showing the fit indices for the three-dimensional Mothers of Preterm Babies Postpartum Depression Scale

\begin{tabular}{lllllllllllllll}
\hline $\begin{array}{l}\text { Number of } \\
\text { items }\end{array}$ & Model $\chi^{2}$ & GFI & AGFI & CFI & TLI & NFI & IFI & SRMR & RMSEA & AIC & BIC & CMIN/DF LO-HI 90 \\
\hline 14 & & & & & & & & & & & & & & \\
\hline 14 (adjusted) & $55.97(41), P=0.06$ & 0.952 & 0.877 & 0.992 & 0.992 & 0.973 & 0.983 & 0.07 & 0.05 & 183.98 & 377.51 & 1.37 & $0.00-0.08$ \\
9 & $22.063(18), P=0.23$ & 0.970 & 0.924 & 0.995 & 0.990 & 0.974 & 0.995 & 0.05 & 0.04 & 76.06 & 157.71 & 1.23 & $0.00-0.08$ \\
\hline
\end{tabular}

Lower Akaike information criterion (AIC) and root mean square error of approximation (RMSEA) scores designate a better fit. AGFI, adjusted goodness of fit index; BIC, Bayesian information criterion; CFI, comparative fit index; CMIN/DF, Chi-square minimum discrepancy/degrees of freedom; GFI, goodness of fit index; IFI, incremental fit index; LO-HI 90, LO 90 and HI 90 are the lower and upper ends of a 90\% confidence interval; NFI, normed fit index; SRMR, standardized root mean square residual; TLI, Tucker-Lewis index. 
Table 6. Three-factor unstandardized and standardized solution for the Mothers of Preterm Babies Postpartum Depression Scale items

\begin{tabular}{|c|c|c|c|c|}
\hline & $\begin{array}{r}\text { Factor } 1 \\
\text { Cognitive and } \\
\text { emotional difficulty }\end{array}$ & $\begin{array}{r}\text { Factor } 2 \\
\text { Hopelessness and } \\
\text { suicidal thought }\end{array}$ & $\begin{array}{r}\text { Factor } 3 \\
\text { Physiological } \\
\text { distress }\end{array}$ & $\begin{array}{r}\text { Proportion } \\
\text { of factor } \\
\text { accounted for }\end{array}$ \\
\hline Cronbach alpha (overall $\alpha=0.86$ ) & $\alpha=0.91$ & $\alpha=0.87$ & $\alpha=0.70$ & \\
\hline $\begin{array}{l}\text { Neglecting personal care, partner's feelings } \\
\text { and other family members because of total } \\
\text { concerns about the baby }\end{array}$ & $1.00(0.00)$ & & & 0.766 \\
\hline $\begin{array}{l}\text { Difficulty concentrating when carrying } \\
\text { out daily routine tasks (washing, cooking, } \\
\text { cleaning) }\end{array}$ & $1.42(0.20)$ & & & 0.965 \\
\hline $\begin{array}{l}\text { Preterm baby care very time-consuming and } \\
\text { stressful }\end{array}$ & $1.18(0.079)$ & & & 0.843 \\
\hline $\begin{array}{l}\text { Feeling like ending it all for me or the baby } \\
\text { to stop being burden to others }\end{array}$ & & $0.91(0.077)$ & & 0.901 \\
\hline $\begin{array}{l}\text { Persistent anxiety that the baby's condition } \\
\text { can never get better (fear of wasting time, } \\
\text { energy, and resources) }\end{array}$ & & $1.08(0.152)$ & & 0.732 \\
\hline $\begin{array}{l}\text { Feeling of hopelessness because of baby's } \\
\text { condition }\end{array}$ & & $1.00(0.00)$ & & 0.922 \\
\hline $\begin{array}{l}\text { Suffers from persistent heartburn and } \\
\text { indigestion }\end{array}$ & & & $1.00(0.00)$ & 0.610 \\
\hline Poor eating habit and appetite & & & $1.65(0.331)$ & 0.804 \\
\hline Consistently having body pains and headache & & & $1.20(0.246)$ & 0.661 \\
\hline
\end{tabular}

Unstandardized loadings and standard error are in parentheses.

Table 7. The intercorrelation coefficients of the factor-based scores (9-item)

\begin{tabular}{|c|c|c|c|c|c|}
\hline Factor dimensions & Mean & SD & 1 & 2 & 3 \\
\hline Cognitive and emotional difficulty & 13.10 & 2.64 & - & $0.391 *$ & $0.350^{*}$ \\
\hline Hopelessness and suicidal thought & 14.36 & 1.96 & & - & $0.607 *$ \\
\hline Physiological distress & 12.68 & 1.48 & & & - \\
\hline
\end{tabular}

SD, standard deviation.

$* P<0.05$ (significant at 0.5 level).

present screening tool like the postpartum bonding questionnaire (PBQ) (Cronbach's alpha 0.87) among a Dutch sample demonstrated meritorious reliability in a study in which it was compared with the Maternal Postpartum Attachment Scale (0.75) and the Mother-to-Infant Bonding Scale (0.67) at 8 and 12 weeks postpartum [22]. Factor analysis showed a threedimension scale that yielded the subdimension of depression, hopelessness, and physiological distress, which were significant correlates of the Edinburgh Postnatal Depression Scale. This finding was similar to the findings of Murray and Cooper [23], who developed the Global Rating Scale to screen women for pregnancy-related disorders among a sample of 51 mothers; they found that the dimension of symptoms included depression, anxiety, and suicidal ideation. The study demonstrated that the new scale had strong convergent validity with the Edinburgh Postnatal Depression Scale. These results support findings from 
Table 8. Normed-valued postpartum depression for mothers of preterm babies delivered in Massey Street Children's Hospital ( $n=152)(14-i t e m)$

\begin{tabular}{lrrrr}
\hline & $\begin{array}{r}\text { Cognitive and } \\
\text { emotional difficulty }\end{array}$ & $\begin{array}{r}\text { Hopelessness and } \\
\text { suicidal thought }\end{array}$ & $\begin{array}{r}\text { Physiological } \\
\text { distress }\end{array}$ & $\begin{array}{r}\text { Postpartum } \\
\text { depression }\end{array}$ \\
\hline Minimum & 6.00 & 5.00 & 3.00 & 14.00 \\
Maximum & 30.00 & 25.00 & 15.00 & 70.00 \\
Mean & 22.38 & 21.36 & 12.38 & 56.84 \\
SD & 3.45 & 2.46 & 1.48 & 7.55 \\
Normed score & 25.83 & 23.82 & 64.63 \\
\hline
\end{tabular}

$\mathrm{SD}$, standard deviation.

other studies that found that incidence of postpartum depression increases in the same direction for the Edinburgh Postnatal Depression Scale and other similar measures of post-partum depression in mothers of preterm babies [24-26].

\section{Recommendations}

This study was a cross-sectional assessment of postpartum depression symptoms among mothers of preterm babies. Early interventions that focus on educating mothers and fathers about the preterm mother could be planned using evidence to inform practitioners about best practices for interventions and provide accurate information about postpartum depression. The study findings revealed that mothers of preterm infants were at higher risk of postpartum depression among those who sought the services of Massey Street Children's Hospital. Health care providers need to be informed that preterm birth has the potential of increasing the risk of postpartum depression, and should plan care in ways that enhance maternal confidence and competence for feeding preterm infants. The health care provider should promote involvement of the father in the care of the preterm infant. The samples were recruited from a state public hospital, and were homogeneous in terms of economic and educational background. One of the drawbacks of using a homogeneous sample is that the external validity of the study is limited. The findings of this study may not be applicable to other settings such as private health clinics, where the income and educational level of the mothers is significantly different. In addition, future studies should compare patients from public and private clinics for their validity and reliability in the Nigerian population. Lastly, given the small number of mothers of preterm infants, our study may not have sufficient statistical power to make inferences regarding the potential contribution of demographic characteristics to postpartum depression among mothers of preterm infants.

\section{Conclusion and limitations of the study}

This study developed and validated the Mothers of Preterm Babies Postpartum Depression Scale among a sample of mothers who delivered preterm babies. The nine-item scale was developed following the established standard and was validated with use of construct and convergent validity methods. The study established that the scale is a reliable measure of postpartum depression of mothers of preterm babies. In conclusion, the new screening tool has shown meritorious validity, and is faster and easier to apply to the obstetric population. The scale has superior ability in early diagnosis of women at risk of postpartum depression between 1 week and 3 months after delivery of a preterm baby.

The limitation of this study includes the lack of comparison with women with full-term babies to ascertain its discriminant validity. Secondly, we relied solely on a single psychiatric evaluation at 6 weeks postpartum and did not control for prior depression during the gestational period. The sample size was small and homogeneous (most were lowincome women), and a multicenter and longitudinal study would have been better. However, the strength lies in the rigorous methodological process undertaken to generate the data and the findings.

\section{Author contributions}

Ajibola A. Ishola and Chisom C. Obasi conceived and presented the idea to I.T. Sholuke. All the authors interviewed the respondents at the pilot study and validation stages, jointly reviewed the items generated results of the experts' face 
validity, and jointly put together the manuscript. A.A. Ishola performed the computations and the analytical methods and interpretation of the results. C.C. Obasi and I.T. Sholuke supervised all the clinical interviews and follow-up with respondents in the study. All the authors discussed the results and the presentation of the results. All the corrections, reviewers' observations, and critical reviews were scrutinized by and the necessary changes were effected by A.A. Ishola. The final draft was edited and reviewed by all the authors.

\section{References}

1. Robinson GE, Stewart DE. Postpartum disorders. In: Stotland NL, Stewart DE, editors. Psychological aspects of women's health care. 2nd ed. Washington: American Psychiatric Press; 2001. pp. 117-39.

2. Danasabe M, Elias N. Postpartum depression among Hausa ethnic women in Abubakar Tafawa Balewa University Teaching Hospital, north east Nigeria. IMPACT Int J Res Humanit Arts Lit 2016;4(3):55-64.

3. American Psychiatric Association. Diagnostic and statistical manual of mental disorders (DSM-5). Washington: American Psychiatric Association Publishing; 2013.

4. Obindo TJ, Ekwempu CC, Ocheke AN, Piwuna CG, Adegbe EO, Omigbodun OO. Prevalence and correlates of postpartum depression in a teaching hospital in Nigeria. Highl Med Res J 2014;13(2):71-5.

5. Ukaegbe CI, Iteke OC, Bakare MO, Agbata AT. Postpartum depression among Igbo women in an urban mission hospital, south east Nigeria. Ebonyi Med J 2012;11(1-2):29-36.

6. Adewuya AO, Fatoye FO, Ola BA, Ijaodola OR, Ibigbami, SO. Sociodemographic and obstetric risk factors for postpartum depression symptoms in Nigerian women. J Psychiatr Pract 2005;11:63-70.

7. Ebeigbe PN, Akigbe AO. Incidence and associated risk factors of postpartum depression in a tertiary hospital in Nigeria. Niger Postgrad Med J 2008;15(1):15-8.

8. Cox JL, Holden JM, Sagovsky R. Detection of postnatal depression. Development of the 10-item Edinburgh Postnatal Depression Scale. Br J Psychiatr 1987;150(6):782-6.

9. Uwakwe R. Affective (depressive) morbidity in puerperal Nigerian women: validation of the Edinburgh Postnatal Scale. Acta Psychiatr Scand 2003;107:251-9.
10. Abiodun O. Postnatal depression in primary care populations in Nigeria. Gen Hosp Psychiatry 2006;28(2):133-6.

11. Owoeye OA, Aina OF, Morakinyo O. Risk factors of postpartum depression and EPDS scores in a group of Nigerian women. Trop Doct 2006;36(2):100-3.

12. Taiwo OJ, Olayinka OO. The validation of Edinburgh Postpartum Depression Scale (EPDS) in north central Nigeria. J Med Trop 2007;9(2):29-40.

13. Howson CP, Kinney MV, Lawn JE. Born too soon: the global action report on preterm birth. Geneva: World Health Organization; 2012.

14. Ogundipe S. Preterm birth, largest killer of newborns on the rampage. Vanguardnews. 2015. Available from: http://www.vanguardngr.com/2015/02/preterm-birth-largest-killer-of-newbornson-the-rampage/. [accessed 12/12/2016].

15. DeVellis RB. Scale development: theory and applications. 3rd ed. Thousand Oaks: Sage; 2012.

16. Churchill GA. A paradigm for developing better measures of marketing constructs. J Mark Res 1979;16:64-73.

17. Nunally JC. Psychometric theory. 2nd ed. New York. McGrawHill; 1979.

18. Anastasi A, Urbina S. Psychological testing. 7th ed. Upper Saddle River, New Jersey: Prentice Hall; 1996.

19. Arbuckle JL. IBM SPSS Amos 24.0 user's guide. Armonk: IBM; 2016.

20. Hu L, Bentler PM. Cutoff criteria for fit indexes in covariance structure analysis: conventional criteria versus new alternatives. Struct Equ Model 1999;6:1-55.

21. Nunnally JC, Bernstein IH. Psychometric theory. 3rd ed New York: McGraw-Hill; 1994.

22. van Bussel JC, Spitz B, Demyttenaere K. Reliability and validity of the Dutch version of the maternal antenatal attachment scale. Arch Womens Mental Health 2010;13(3):267-77.

23. Murray L, Cooper PJ. Postpartum depression and child development. New York: Guilford Press; 1997.

24. Brockington IF, Oates J, George S, Turner D, Vostanis P, Sullivan M, et al. A screening questionnaire for mother-infant bonding disorders. Arch Womens Mental Health 2001;3: 133-40.

25. Brockington IF, Fraser C, Wilson D. The postpartum bonding questionnaire: a validation. Arch Womens Mental Health 2006;9:233-42.

26. Tahirkheli NN, Cherry AS, Tackett AP, McCaffree MA, Gillaspy SR. Postpartum depression on the neonatal intensive care unit: current perspectives. Int J. Women's Health 2014;6:975-87. 